\title{
Factors Causing Stress among Working Women and Strategies to Cope Up
}

\author{
Dr. Latha Krishnan \\ Director, Department of Management Studies Sona College of Technology, Salem, Tamilnadu
}

\begin{abstract}
Families today are seeing rapid changes due to the increased pace of growth and modernization. Indian women belonging to all classes have entered into various professions which causes stress in their personal and professional life. Women's exposure to educational opportunities is significantly higher than it was some years ago, especially in the cities. Our study have identified socio-economic stressors, psychological and family and relationship stressors causing stress among working women and strategies to cope up with it, though study was conducted among working women in different sectors in Bangalore city. A sample of 100 respondents was chosen on the basis of stratified random sampling technique. Statistical tools like factor analysis and regression coefficient were used to develop Structural Equation Model. The findings of the study reveal that under socio-economic stressors unexpected guests, followed by absence of domestic help causes major stress among working women. Similarly being perfectionist with unnecessary worries which cause psychological set back among working women. Moreover anxiety about children future and husbands job insecurity play a major role in causing stress under family and relationship. Thus the working women need to have work life balance and imbibe stress management strategies like meditation, balanced diet filled with entertainment and fun to lead a stress free life.
\end{abstract}

Keywords: Socio-Economic Stressors, Psychological Stressors, Family and Relationship Stressors, Stress Management Strategies.

\section{Introduction}

The term 'stress' has different importance for researchers in diverse discipline. Study conducted by different researchers stress is associated even in relation to ecosystem and population of organisms. Biologists refer to temperature, cold and insufficient food supply as being sources of stress. Social scientists are more concerned about people's contact with their situation and the resulting emotional disturbances as causes of stress. Stress is anything that disrupts the routine, physical or mental well-being of individuals. It occurs when the body performs beyond his capabilities or when a person faces unusual demands. A simple demonstration of stress may be a bad temper while a severe display may be an act of violent behavior. A stressor is a cause that creates stress. A stressor can be either positive or negative on the basis of how person reacts. For example, one person may view stressor as a motivator, whereas another person may identify it as a constraint. Stress can be positive or negative. Positive stress is known as estruses and negative stress as distress. Distress affects physical and mental well being of a person. Estruses trigger the body and mind to perform creatively. Distress has a negative stress which affects the mental composure of a person. Some of these problems are insomnia, eating disorders, heart problems, and suicidal tendencies.

Devoid of stress, a person becomes sluggish and boring. Positive stress encourages a person to achieve better. However, if this stress exceeds beyond the required level it causes distress. The perception of stress varies among individuals and they have their own stress endurance as some tend to work better under pressure, while the others cannot bear 'last minute syndrome'.

\section{Review Of Literature}

Our family situations are entwined with stress and strains where working women they have to cope up with all pressures at work as well as at home. Pearlin and $\operatorname{Schooler}^{3}(1978)$ reported that the stressors, not only affects major life events but also encompasses ongoing minor events like electricity failure, maid not turned up, unexpected guests and child's misbehavior. Stress is not uncontrollable. With proper understanding of the stressors that cause stress, the situation can be well managed. In India research on family stress management had been of low concern because of lack of awareness and importance of stress in our family life. Kapur ${ }^{4}(1974)$ indicated that women who choose to combine marriage with career face a situation of helplessness and they hardly know how to allocate time and resources between these two major responsibilities. Paterson ${ }^{5}$ (1978) confirmed that the job taken by women created more conflicting situations for them due to dual role played and inability to tolerate the whole burden. Similarly, Holahan and Gilbert ${ }^{6}(1979)$ also reported that women who assumed home roles (e.g. wife, mother and a home maker) and non home roles (e.g. employee) frequently experienced conflict between competing role demands. Conflicts were considered likely when women perceived 
their home and career roles as highly desirable but mutually exclusive. Gutek ${ }^{7}$ et al (1981) found that the interrole conflict is likely to increase as the demands of either the work role or family role increases. Similarly, interrole conflict can increase as one's obligations to the family expand through marriage and the arrival of children. However, Barnett and Baruch ${ }^{8}$ (1985) found that role conflict and levels of overload were significantly associated with occupying the role of mother but were not significantly associated with occupying the role of paid worker or wife. In opinion of Frone M.R. Russell ${ }^{9}$ (1992) combination of career and family roles are often associated with conflict, overload and stress. Pareek and Mehta ${ }^{10}$ (1997) in their study compared three groups of working women i.e. gazetted officers, bank employees and school teachers on the types of role stresses they experienced.

The specific objectives of the study are:

\section{Objectives}

1. To examine the various factors contributing to stress among working women.

2. To identify the impact of the stress management techniques used by working women.

3. To analyze the mental and physical stress among working women.

\section{Methodology}

This study was conducted among working women in different sectors in Bangalore city. The sample size consists of 100 respondents namely working who were chosen on the basis of stratified random sampling technique. The study was based on both primary and secondary sources of information. Percentage Analysis, mean scores and Chi-square were used for testing the hypotheses and interpretation of data. Factor analysis and regression coefficients were used to develop structural equation model.

\section{Hypotheses}

\section{Results And Discussions}

I. Mental and Physical stress management techniques reduces the level of stress among women.

1. (a) There is no difference in attitude towards stress management techniques among working women.

1. (b) Physical stress and mental stress among working women are independent.

\section{(i) Profile of the Respondents}

The profile reveals that majority of the working women were in the age group of 30-50 years. Maximum number of women (62.67\%) was educated up to graduation level and the others are professionals. Maximum number of families $(76.60 \%)$ were medium size with 4- 6 members. Maximum number of women (69.40\%) were having the day length between 16-18 hours. Most of the women (78.8\%) were getting assistance from servant for doing household work especially working women. Most of the working women (98.67\%) have full time jobs, which needed mental work. Working hours varied between 7-8 hours for most of the women.

\section{(ii) Socio-economic stressors}

Data presented in Table 1 reveals the sociological factors affecting stress among working women. Even among working women as their income goes up expenditure also goes up and it constitute certain level of stress due to job insecurity. Significant difference was observed due to stressor 'unexpected guests'. Working respondents (mean score 0.93 ranked 1) were more stressed due to this factor. This is because of shortage of time and overburden of work; it is difficult for them to attend the guests. Stress due to troubles with in laws was given last rank by working respondents. It was observed that working women tend to spend less time with in laws. There is significant difference in the attitude of working women regarding the absence of servant maid. This act as stressors ranked number 2 by working women. It is inferred that absence of servant maid causes stress due to cluttering of things at home for working women. On an average it was found that working respondents were more stressed due to sociological factors of stress.

Table 1 Socio-Economic Stressors among Working Women

\begin{tabular}{|l|c|c|c|}
\hline Socio-Economic factors & Variable code & \multicolumn{2}{|c|}{$\begin{array}{c}\text { N= 100 } \\
\text { Working Women }\end{array}$} \\
\cline { 3 - 4 } & & Mean Score & Ranks \\
\hline Interference of relatives and neighbors & Var1 & 0.63 & 6 \\
\hline Absence of servant or Domestic help & Var2 & 0.81 & 2 \\
\hline Unexpected guests & Var3 & 0.93 & 3 \\
\hline Compulsory socialization & Var4 & 0.68 & 5 \\
\hline Financial pressures & Var5 & 0.65 & 7 \\
\hline Troubles with in-laws & Var6 & 0.62 & 4 \\
\hline Lack of social support & Var7 & 0.66 & 3 \\
\hline
\end{tabular}


Source: Primary Data

\section{(iii) Psychological stressors}

It is interesting to note that perfectionism and unnecessary worries (mean score $0.81 \& 0.75$ ) constitute major stressors for working women in table 2. Working women are good performers and expect perfectionism in all walks of life which leads to stress most of the time. One husband asserted that his wife expects every one to do perfect job and keep nagging him and the children and blaming them for not going a good job and get stressed in turn.

Table 2 Psychological Stressors Among Working Women

\begin{tabular}{|l|c|c|c|}
\hline \multirow{2}{*}{ Psychological Factors } & Variable code & \multicolumn{2}{|c|}{$\begin{array}{c}\text { N= 100 } \\
\text { Working Women }\end{array}$} \\
\cline { 3 - 4 } & & Mean Score & Ranks \\
\hline Pessimistic Attitude & Var1 & 0.64 & 6 \\
\hline Perfectionism & Var2 & 0.81 & 5 \\
\hline Low self esteem & Var3 & 0.66 & 3 \\
\hline Procrastination & Var4 & 0.73 & 4 \\
\hline Temperament / anger & Var5 & 0.68 & 7 \\
\hline Lack of assertiveness & Var6 & 0.58 & 2 \\
\hline Unnecessary worries & Var7 & 0.75 & \\
\hline
\end{tabular}

Source: Primary Data

\section{(iv) Family and relationship stressors}

Stressors related to children, respondents gave first rank to 'anxiety about children's future' (mean score 1.44) followed by stressors related to husband, respondents gave second rank to 'husband's job insecurity' as a factor of stress mean score 1.32. Thus it is inferred that the women gives top priority towards children and husband and any discomfort in this zone causes extreme stress to them. Significant difference was observed in working respondents regarding adjustment to marriage. It was found in table 3 that working women were having more difficulty in adjusting to marriage. Intergeneration problems and care of children in her absence is as a factor of stress having rank seventh and fifth respectively. Majority of respondents in the sample did not regard 'childlessness' and 'more children' as a factor of stress because they were not facing these problems.

Table 3 Family and Relationship Stressors among Working Women

\begin{tabular}{|l|c|c|c|}
\hline \multirow{2}{*}{ Family and Relationship Factors } & Variable code & \multicolumn{2}{|c|}{$\begin{array}{c}\text { N= 100 } \\
\text { Working Women }\end{array}$} \\
\cline { 3 - 4 } & & Mean Score & Ranks \\
\hline Marital disagreement & & 0.84 & 3 \\
\hline Rebellion teens & Var1 & 0.81 & 5 \\
\hline Caring for ill family members & Var2 & 0.78 & 6 \\
\hline Children with special needs & Var3 & 0.73 & 1.44 \\
\hline Anxiety about children's future & Var4 & 1.32 & 2 \\
\hline Husband's job insecurity & Var5 & 0.25 & 9 \\
\hline None to care children in absence & Var6 & 0.28 & 8 \\
\hline Husband's unhealthy habit & Var7 & 0.56 & 7 \\
\hline Inter generation problems & Var8 & \\
\hline
\end{tabular}

Source: Primary Data

\section{(iv) Mental and Physical stress management strategies adopted among working women}

It is observed in table 4 that the use of sleeping pills and tranquilizers was given last rank by the respondents. Data also makes it clear that no respondent are making the use of alcohol and mood altering drugs. The low scores give to all the medicinal methods reveal that very few of the respondents are making the use of these techniques. This may be due to the reason that they were not considering these techniques as effective and might be seeing some side effects of these techniques.

Majority of respondents from both the categories are adopting physical stress management strategies related to relaxation, body therapy, diet. Effectiveness of these techniques is also reported by many research work like exercise and relaxation (Nelson and Nelson 1981 ${ }^{11}$ ), music (Litle 1986), balanced diet (King and Parham $1981^{12}$ ) are different physical stress management strategies which are effectively used by the women.

There is no significant difference in the use of mediation techniques among working women respondents. From the data, it was found that first rank was given to 'positive thinking' as a method to overcome stress. It was observed that the working women are better time managers. It was stated by one of the working women that we teach time management to our students but we fail to practice on our own. 
Table 4 Mental and Physical Stress Management Strategies Adopted Among Working Women

\begin{tabular}{|l|c|c|c|}
\hline Stress Management strategies & Variable code & \multicolumn{2}{|c|}{$\begin{array}{c}\text { N= 100 } \\
\text { Working Women }\end{array}$} \\
\cline { 3 - 4 } & & Mean Score & Ranks \\
\hline Meditation & & 2.20 & 1 \\
\hline Breathing exercises and yoga & Var1 & 0.81 & 6 \\
\hline Exercises, jogging and walking & Var2 & 0.74 & 7 \\
\hline Social support & Var3 & 0.68 & 8 \\
\hline Psycho-therapy & Var4 & 0.94 & 5 \\
\hline Entertainment and fun & Var5 & 1.44 & 2 \\
\hline Balanced diet & Var6 & 1.6 & 4 \\
\hline Nature care and body massage & Var7 & 1.25 & 9 \\
\hline Time Management & Var8 & 0.58 & 10 \\
\hline Music and instruments & Var9 & 0.56 & 11 \\
\hline Sleeping pills and tranquilizers & Var10 & 0.36 & \\
\hline
\end{tabular}

Source: Primary Data

\section{Hypothesis Testing}

Table Value of $\mathrm{F}$ for $\mathrm{V}_{1=3}$ and $\mathrm{V}_{2}=6$ at $5 \%$ level of significance is 4.76 . The calculated value is 1.2 which is less than the table value, it is inferred that there is no difference in attitude towards stress management techniques among working women.

The calculated $\mathrm{F}$ value for the hypothesis $1(\mathrm{~b})$ is 9.6 , which is more than the table value of 5.14 at $5 \%$ level of significance. Since the F value is more than the table value, it is inferred that physical stress and mental stress among working women are dependent, as the mental stress due to work life and family leads to physical stress.

Hence the hypothesis 1 (a) "There is no difference in attitude towards stress management techniques among working women" is accepted, and the hypothesis 1 (b) "Physical stress and mental stress among working women are independent" is rejected.

\section{Structural Equation Model}

In order to know the association of dependency or independency between the variables linear regression and factor analysis was performed to mold the variables in a path model which is shown in the fig 1 . All the 23 stress causing variables or stressors were rotated in factor component matrix and factor analysis compiled the diverse variables into three components (eigen values $\geq 1$ ) after attaining the Measures of Sampling Adequacy value $\geq 0.600$ for all the variables in a correlation matrix. The three component factors have been labeled as:

1) Family and Relationship Stressors: Nine variables were billed under family and relationship stressors by factor analysis as listed in table 3 accounted for highest factor loading of 31.40 in the whole component plot matrix. The regression coefficients have also been assigned to the individual variables as shown in fig 1 . The highest regression coefficient is shown by var5 $(\mathrm{r}=39.45)$, followed by var6 $(\mathrm{r}=38.72)$, var2 $(\mathrm{r}=25.12)$ and var3 (25.09) while as the lowest regression coefficient was shown by var8 ( $\mathrm{r}=20.04)$, followed by var7 ( $\mathrm{r}=21.12)$, $\operatorname{var} 9(\mathrm{r}=21.19)$ and $\operatorname{var} 1(\mathrm{r}=21.22)$.

2) Socio-economic stressors: seven variables were owed under socio-economic stressors by factor analysis as listed in table 1 accounted for second highest factor loading of 30.22 in the whole component plot matrix. The regression coefficients have also been assigned to the individual variables as shown in fig 1 . The highest regression coefficient is shown by var5 $(\mathrm{r}=34.01)$, followed by var6 $(\mathrm{r}=33.78)$, var2 $(\mathrm{r}=25.12)$ and var4 (27.41) while as the lowest regression coefficient was shown by var7 ( $\mathrm{r}=22.66)$, followed by var2 $(\mathrm{r}=23.23)$ and $\operatorname{var} 3(\mathrm{r}=24.87)$.

3) Psychological Stressors: Seven variables were allocated under psychological stressors by factor analysis as listed in table 2 accounted for third highest factor loading of 26.32 in the whole component plot matrix. The regression coefficients have also been assigned to the individual variables as shown in fig 1 . The highest regression coefficient is shown by var3 ( $\mathrm{r}=29.00)$, followed by var1 $(\mathrm{r}=28.54)$, var5 $(\mathrm{r}=25.23)$ and var4 (24.34) while as the lowest regression coefficient was shown by var2 $(r=23.03)$, followed by $\operatorname{var} 6(r=23.91)$ and $\operatorname{var} 7(\mathrm{r}=24.02)$.

The SEM in Fig. 1 shows nine variables labeled (see table 4) under stress management strategies followed by people in fig. 1, the respective regression coefficients have also been assigned to the variables. The highest regression coefficient is shown by var1 ( $\mathrm{r}=38.74)$, followed by $\operatorname{var} 7(\mathrm{r}=38.34)$, var3 ( $\mathrm{r}=36.76)$, var6 
$(\mathrm{r}=36.20)$, $\operatorname{var} 9(\mathrm{r}=35.09)$ and $\operatorname{var10}(34.87)$ while as the lowest regression coefficient was shown by var11 $(r=19.06)$, followed by var4 $(r=22.30)$, var8 $(r=25.55)$, var2 $(r=29.06)$ and $\operatorname{var} 5(r=32.12)$.

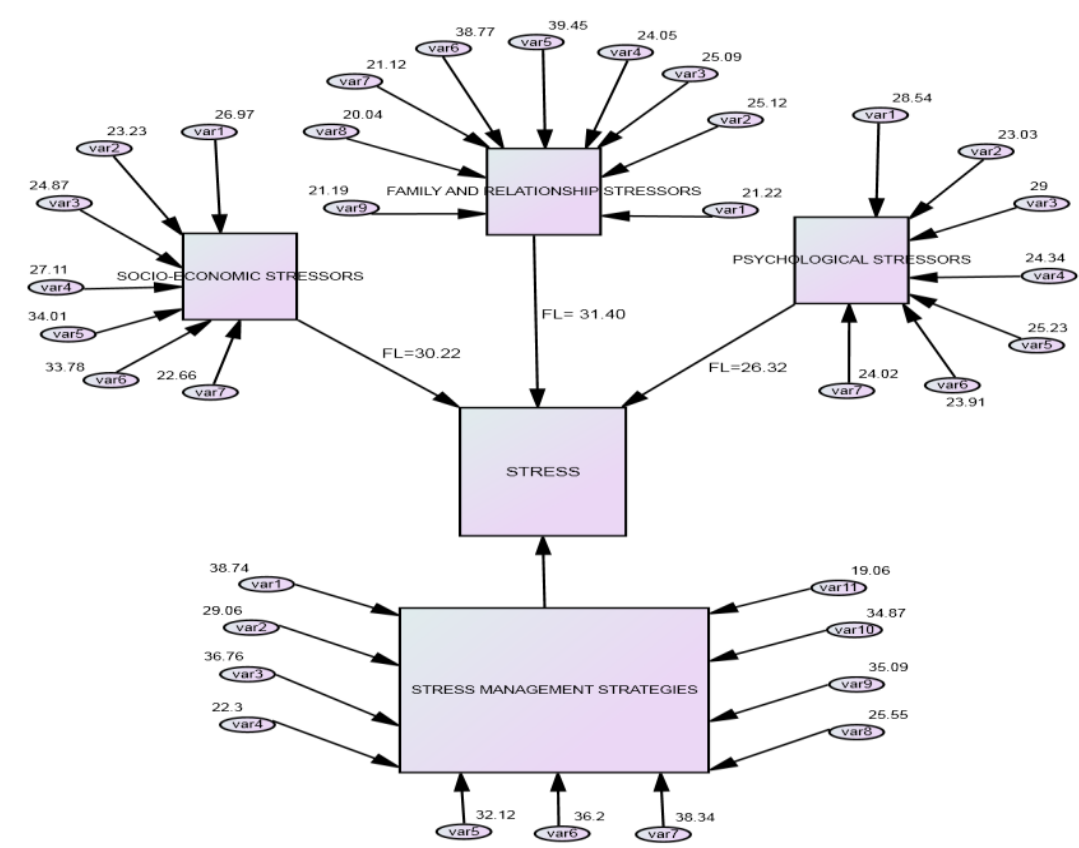

Source: Developed by Author

Figure 1 Path Model

\section{Conclusion}

Economic conditions of inflation, desire to maintain high standard of living, or develop "one's identity" are contributing to the economic push of women into the work force. Thus, financial burden is stated as main stressors among working women. But as women increasingly gain occupational mobility, they are not only exposed to the same physical hazards of work environment as men but also exposed to the pressures created by multiple role demands and conflicting expectations. By fulfilling their economic needs, employment has no doubt made women independent with an identifiable social status but it has also made them to juggle into two main domains of life- work and family. They have stepped into work place but the role responsibilities of women still remain the same. Multi-tasking is the buzzword these days for working women. An individual requires special skills to perform multiple tasks simultaneously. One way to minimize stress while multi-tasking is to plan, prioritize, and perform. It can thus be concluded that working women were significantly more stressed.

It is also important to broaden the horizons of one's mind right from one's youth so that one can overcome the possessiveness excessive attachment, too many \& choosy expectations from family members (which are usually responsible for discord \& bitterness in family). One should be flexible about this point. Dependence to some extent is many times inevitable and hence should not be taken as pitiability. This involves efforts to acquire physical, instinctual, emotional \& intellectual well being. In addition, total well being pertains not merely to an individual (analogous to a cell) but to whole mankind in fact whole universe (analogous to an organism).

\section{References}

[1]. Joshi, B. K. Stress Management, Published by Mrs. Shashi Jain for painter publishers 2007, 1st Edition.

[2]. Aujla, P., H. R. Gill and Sandhu, P. "Sociological and Environmental Factors Causing Stress Among Women and Fighting Techniques Used", J. Hum. Ecol., 15(3): 207-213 (2004)

[3]. Pearlin, L. and C. Schooler, The structure of coping. Journal of Health, Society and Behaviour, 19,1978, 2- 21

[4]. Kapur, P. Changing Status of the Working Women in India, Delhi: (Vikas Publishing House Pvt. Ltd. 1974)

[5]. Paterson, L. R. An Exchange Analysis of Family Roles and Marital Satisfaction, Diss. Abst. Int., 38, 1978, 46-57.

[6]. [Holahan, C., \& I. Gilbert, (1979). Conflict Between Major Life Roles: Women and Men in Dual Career Couples. Human Relations, 32, 1979, 451- 467.

[7]. Gutek, B.A., C. Y., Nakamura and Nieva, V. The Interdependence of Work and Family Roles. Journal of Occupational Behaviour, 2,1981, 1-16.

[8]. Barnett, R.C., and G. K. Baruch, Women's Involvement in Multiple Roles, and Psychological Distress, Journal of Personality and Social Psychology, 49, 1985, 135-145. 
[9]. Frone, M.R., M. Russell, and Cooper, M. L. (1992). Antecendents and Outcomes of Work-Family Conflict: Testing a Model of Work-Family Interface. Journal of Applied Psychology, 77, 1992, 65-78.

[10]. Pareek, A. and M. Mehta, Role Stress Among Working Women, in D.M. Pestonyee, \& U. Pareek (Eds), Studies in Organizational Role Stress and Coping (pp. 173-181). New Delhi: Nice.1997

[11]. Nelson, P. T. and C. W. Nelson, Personal and family stress management, J. Home. Econ., 73(3), 1981, 34- 36.

[12]. King, L. S. and E. S., Parham, The Diet Stress Connection, J. Home. Econ., 73(3), 1981, 25-28. 